\title{
MODELAGEM DA RELAÇÃO HIPSOMÉTRICA PARA BRACATINGAIS DA REGIÃO METROPOLITANA DE CURITIBA-PR
}

\author{
Alexandra Consuelo de Plácido e Silva Bartoszeck ${ }^{1}$ \\ Sebastião do Amaral Machado ${ }^{2}$ \\ Afonso Figueiredo Filho ${ }^{3}$ \\ Edílson Batista de Oliveira ${ }^{4}$
}

\begin{abstract}
RESUMO
Este trabalho teve como objetivo testar vários modelos tradicionais e outros genéricos para o ajuste da relação hipsométrica para povoamentos de bracatinga (Mimosa scabrella Benth) da Região Metropolitana de Curitiba, Paraná. Os dados foram obtidos em 20 parcelas permanentes, cujos diâmetros e alturas foram medidos aproximadamente aos 4, 5, 6 e 7 anos de idade e de 124 parcelas temporárias, cobrindo idades de 3 a 18 anos. A existência de dados em vários sítios, idades e densidades permitiu realizar ao todo 751 análises envolvendo a combinação de 23 modelos com três classes de sítios (índices de sítio: 16,8; 13,5 e 10,2 m), idades de 4 a 7 anos para as parcelas permanentes e 3 a 18 para as temporárias, e quatro tratamentos de densidade inicial (testemunha, 2000, 4000 e 8000 árvores/hectare), sendo as temporárias sem tratamento algum. O Índice de Ajuste de Schlaegel (IA), o erro padrão da estimativa em porcentagem $\left(\mathrm{S}_{\mathrm{yx}} \%\right)$, seguida da análise de resíduos foram os testes usados para selecionar o melhor modelo. Como se obteve um grande número de combinações e como nenhum dos modelos foi sempre o melhor para todas as combinações, procedeu-se a um ordenamento dos mesmos (ranking) usando as estatísticas (IA e $\mathrm{S}_{\mathrm{yx}} \%$ ) para verificar qual dos modelos que, de forma genérica apresentasse a melhor performance. Para as parcelas temporárias e a combinação destas com as testemunhas das parcelas permanentes, os modelos genéricos desenvolvidos por regressão passo a passo tiveram melhor performance. Estes modelos envolveram características do povoamento, tais como, altura dominante $\left(\mathrm{h}_{\text {dom }}\right)$ e diâmetro médio quadrático $\left(\mathrm{d}_{\mathrm{g}}\right)$.

Palavras-chave: bracatinga (Mimosa scabrella), relação hipsométrica, modelos tradicionais, modelos genéricos
\end{abstract}

\section{MODELLING HEIGHT-DIAMETER RELATIONSHIP FOR Mimosa scabrella STANDS IN THE CURITIBA METROPOLITAN REGION}

\begin{abstract}
This research was developed in order to test several traditional end generic models to fit the height-diameter relationship for stands of bracatinga (Mimosa scabrella Benth.) in the Curitiba Metropolitan Region. The data came from 20 permanent sample plots $\left(325 \mathrm{~m}^{2}\right.$ each), whose diameter and heights were measured approximately at ages 4, 5, 6 and 7 years and from 124 temporary sample plots covering ages from 3 to 18 years. The availability of data in several sites, ages and densities made possible to accomplish 751 analysis involving the combination of these mathematical models with three site classes (site indexes: 16.8; 13.5 and $10.2 \mathrm{~m}$ ), ages from 4 to 7 years for the permanent plots and from 3 to 18 years for the temporary ones, and four treatments (control, 2000, 4000 and 8000 trees/hectare), being the temporary ones without any treatment. The Schlaegel fitting index (I.A.), the standard error of estimate in percent (syx \%), followed by analysis of residuals were used to select the models. The existence of a large number of combinations, and given that none of the models was always the best for all combinations, led to the ranking based on I.A. and syx \% to identify the best performance. Thus, for the permanent plot data, the Curtis model was the best one. For the temporary plots data, the generic models developed by stepwise procedure provided the best performance. These generic models involved characteristics of the stands, such as, dominant height and quadratic mean DBH.

Key-words-: "bracatinga" (Mimosa scabrella Benth.), height-diameter relationship, traditional models, generic models.
\end{abstract}

\footnotetext{
${ }^{1}$ Engenheira Florestal, M. Sc., professora adjunta da UNIANDRADE. Email: abartoszeck@alternex.com.br

${ }^{2}$ Engenheiro Florestal, M.Sc., Ph.D., professor sênior da UFPR, pesquisador 1 - A do CNPq. Email: $\underline{\text { sammac@ @loresta.ufpr.br }}$

${ }^{3}$ Engenheiro Florestal, M.Sc., Ph.D., professor sênior da UFPR e professor da UNICENTRO, pesquisador 2 - B do CNPq

${ }^{4}$ Engenheiro Agrônomo, M.Sc., Ph.D., pesquisador da EMBRAPA - Floresta
} 


\section{INTRODUÇÃO}

A bracatinga (Mimosa scabrella Benth.) é uma leguminosa florestal nativa das áreas subtropicais das regiões sul e sudeste do Brasil, destacando-se como espécie pioneira, associada às florestas com Araucaria angustifolia (Floresta Ombrófila Mista), em campos originados depois das explorações florestais (Klein, 1960).

A bracatinga vem sendo cultivada no sul do Brasil desde o início do século XX. No Estado do Paraná, o incentivo ao seu plantio iniciou-se a partir de 1909, devido à intensa propaganda que visava atender a demandas energéticas (Hoehne, 1930a; Martins, 1944). Este fato foi de grande estímulo para o surgimento do sistema agroflorestal tradicional da bracatinga, que segundo Baggio et al. (1986), pode ser considerado o mais antigo sistema de produção racional de lenha no sul do Brasil, totalmente desenvolvido com base na vivência prática dos agricultores.

Na Região Metropolitana de Curitiba, Estado do Paraná, os bracatingais cobrem aproximadamente 60.000 ha, distribuídos, principalmente, em cerca de 3000 pequenas propriedades (Mazuchowski, 1990). É uma espécie que fornece madeira para construção civil, varas para olericultura, madeira serrada, peças torneadas, aglomerados, compensados, celulose, além de ser utilizada como planta apícola e forrageira. É bastante ornamental, sendo aproveitada com sucesso em paisagismo e, devido às características de espécie pioneira (rápido crescimento, heliófita, etc.) é recomendada na recuperação de áreas degradadas, conservação de solos, pois através da deposição de biomassa e de nutrientes, fertiliza o solo (Baggio,1994).

No entanto, a sua mais importante utilização é na produção de energia como carvão vegetal e lenha para indústrias e consumo doméstico, tendo como vantagem a baixa produção de fumaça. Portanto, com todas estas características, por seus múltiplos usos e grande mercado, o bracatingal desempenha um papel importante na economia de muitas propriedades rurais, constituindo-se em uma das principais fontes de renda. Entretanto, o seu manejo continua sendo feito da forma tradicional, que pode não ser a maneira mais adequada de condução.

De acordo com Embrapa (1988), o sistema tradicional de produção de bracatinga é realizado em propriedades agrícolas com até 50 ha e, caracteriza-se pela facilidade de manejo e rentabilidade que oferece. $\mathrm{O}$ bracatingal desempenha, na maioria das propriedades, o papel de "poupança verde", onde a expectativa do produtor é a obtenção de uma renda monetária segura, com minimização do fator mão-de-obra.

Em inventários florestais, a variável diâmetro à altura do peito é facilmente medida para todas as árvores; a altura, no entanto obtida de modo direto através de instrumentos apropriados, fornece resultados acurados, porém não econômicos, devido ao tempo gasto. Portanto, é comum a medição do diâmetro de todas as árvores das parcelas e a altura apenas em algumas delas. O conjunto de dados de alturas das árvores medidas, com os respectivos diâmetros, é usado para estabelecer uma relação de regressão da altura sobre diâmetro, a qual é empregada para estimar as alturas das demais árvores da parcela em função dos diâmetros já medidos. Logo, estima-se a variável de difícil acesso em função da mais fácil e de rápida medição, reduzindo-se, portanto, o tempo e custos de mensuração.

Os modelos de relação hipsométrica que consideram fatores como: sítio, idade e densidade, são de difícil obtenção; assim, deve-se estudar a viabilidade da aplicação de uma equação genérica, o que eliminará o trabalho de ajuste e seleção de modelos para cada parcela ou povoamento. Em vista do exposto, este trabalho objetivou testar e comparar modelos de relação hipsométrica para as diferentes combinações de idade, sítio e densidade das parcelas permanentes e temporárias de bracatingais da Região Metropolitana de Curitiba e também a possibilidade de agrupar os dados das parcelas permanentes e temporárias a fim de gerar uma equação genérica. 


\section{MATERIAIS E MÉTODOS}

\section{Localização e caracterização da área de estudo}

Para a realização desta pesquisa foram utilizados dados provenientes de 20 parcelas permanentes, remedidas 6 vezes e 124 parcelas temporárias, instaladas e medidas em várias localidades da Região Metropolitana de Curitiba, incluindo 14 municípios, os quais abrangem uma área total de 876.300 ha, sendo que, aproximadamente, 60.000 ha estão cobertos com bracatingais, ou seja, 5,7\%. As parcelas permanentes foram estabelecidas nos municípios de Colombo e Bocaiúva do Sul, enquanto as temporárias se localizaram nos municípios de Bocaiúva do Sul, Colombo, Campina Grande do Sul, Campo Largo, Balsa Nova, Almirante Tamandaré, Rio Branco do Sul, Contenda, Araucária, Piraquara, Quatro Barras, São José dos Pinhais, Quitandinha, e Agudos do Sul, todos no Estado do Paraná, Brasil. Esses municípios situam-se entre as latitudes $25^{\circ} 11^{\prime}$ e $25^{\circ} 49^{\prime} \mathrm{S}$ e entre as longitudes $49^{\circ} 05^{\prime}$ e $49^{\circ} 43^{\prime} \mathrm{W}$.

Segundo o sistema de classificação de Koeppen, o tipo climático regional, onde as parcelas permanentes e temporárias foram instaladas, é $C f b$, que corresponde ao clima temperado propriamente dito, mesotérmico úmido sem estação seca definida, com quatro estações bem definidas, com verões quentes e chuvosos e invernos frios com períodos secos eventuais. A temperatura média do mês mais frio é inferior a $18^{\circ} \mathrm{C}$ e os verões são frescos com a temperatura média do mês mais quente em torno de $22,6^{\circ} \mathrm{C}$. Em virtude da altitude e do derrame de ar frio de frente polar, devem ser esperadas, em média, mais de 10 até 25 geadas noturnas por ano (Maack, 1981; IAPAR ,1994).

Os municípios onde as parcelas permanentes foram instaladas apresentam precipitação média anual de $1.400 \mathrm{~mm}$ e umidade relativa do ar de $80 \%$. A precipitação máxima ocorre no mês de janeiro e as mínimas entre abril e agosto, com $200 \mathrm{~mm}$ e 75 a 100 mm/mês, respectivamente (Maack, 1981; IAPAR , 1994).

Em quase a totalidade da superfície da Região Metropolitana de Curitiba, a ocorrência da bracatinga se apresenta em altitudes superiores a $700 \mathrm{~m}$ acima do nível do mar e predominam os solos do tipo Cambissolos, com diferentes graus de profundidade e fertilidade. Em geral são solos pobres, pouco desenvolvidos e dispostos em um relevo bastante ondulado, com inclinações diversas. São solos ácidos, com elevadas concentrações de alumínio e baixa saturação de bases. Predominam as texturas argilosas e ricas em matéria orgânica no horizonte $\mathrm{A}$, apresentando boa drenagem (Baggio, 1994).

\section{Parcelas permanentes}

Os dados das parcelas permanentes resultaram da implantação de experimento pelo pesquisador Antonio A. Carpanezzi do Centro Nacional de Pesquisa de Florestas (Embrapa Florestas). O delineamento utilizado foi o em blocos ao acaso. Cada bloco, em número de cinco, constituiu-se de 4 parcelas de $325 \mathrm{~m}^{2}$ $(13 \times 25 \mathrm{~m})$ e ao redor das mesmas foram deixadas bordaduras de $5 \mathrm{~m}$.

Após a implantação, foram efetuados desbastes nas parcelas e bordaduras, conforme sorteio, para que apresentassem as diferentes densidades desejadas. Estes desbastes foram executados com foice, seguido de uma roçada, para eliminar a "mato-competição".

Com base nos dados do levantamento preliminar das sub-parcelas, foram retiradas as árvores menores e após o desbaste realizou-se nova medição da altura de todas as árvores remanescentes, a qual corresponde à medição 1. Na tabela 1 são apresentadas as densidades, incluindo as parcelas sem desbaste (testemunha)

Tabela 1: Tratamentos de densidade inicial Table 1: Treatments of initial density

\begin{tabular}{c|c|c}
\hline Tratamento & $\mathbf{N}^{\mathbf{0}}$ de árvores /ha & $\mathbf{N}^{\mathbf{0}}$ de árvores/parcela \\
\hline \hline 1 & testemunha & Total das árvores \\
2 & 2.000 & 65 \\
3 & 4.000 & 130 \\
4 & 8.000 & 260 \\
\hline
\end{tabular}


Após o desbaste, foram realizadas medições anuais até a idade de 7,5 anos. Nas duas primeiras medições, foram obtidas a altura total $(h)$ das árvores e determinou-se o número de árvores/ha $(N)$ e, nas seguintes, além da altura e densidade, mediu-se o diâmetro à altura do peito $(d)$. Não houve medição na idade de três anos. Foram utilizadas varas telescópicas para medir as alturas e sutas para os diâmetros.

Como as remedições dos blocos não foram realizadas na mesma época, os meses foram transformados em frações decimais de anos para realização das análises posteriores. Assim, as idades foram: 1,0; 2,0; 2,2; 3,9; 4,1; 4,$2 ; 4,8 ; 5,0 ; 5,4 ; 6,3$ e 7,6 anos. Para esta pesquisa foram utilizadas as parcelas com idades a partir de 3,9 anos; pois, para as idades 1,$0 ; 2,0 ; 2,2$ anos não foram obtidos dados da variável diâmetro.

Na propriedade de Daniel Rosenente (ADR, BDR) foram instalados dois blocos e nas demais propriedades somente um bloco, perfazendo um total de cinco blocos.

\section{Parcelas temporárias}

Paralelamente, o já mencionado pesquisador da Embrapa Florestas instalou e mediu o diâmetro e a altura total em 77 parcelas temporárias, em bracatingais nativos, com idades variando de 3 a 18 anos, principalmente nos Municípios de Colombo, Bocaiúva do Sul e Campina Grande do Sul, todos no Estado do Paraná. Posteriormente, foram medidas mais 10 parcelas para reforçar o conjunto de dados nas idades de 10,11 e 12 anos. As alturas foram medidas com vara telescópica e os diâmetros com suta.

A Companhia de Energia Elétrica do Paraná (COPEL), Divisão de Meio Ambiente, cedeu dados de medições de mais 37 parcelas, com idades entre 3 e 13,5 anos, localizadas nos municípios de Campo Largo, Balsa Nova, Almirante Tamandaré, Rio Branco do Sul, Contenda, Araucária, Piraquara, Quatro Barras, São José dos Pinhais, Quitandinha, e Agudos do Sul. As alturas foram medidas com vara telescópica e os diâmetros com fita métrica.

As parcelas temporárias foram submetidas a manejo tradicional, ou seja, a densidade inicial permaneceu inalterada após as capinas.

\section{Classificação de sítio}

Para classificar o sítio, tanto das parcelas permanentes como das temporárias, utilizou-se a equação desenvolvida por Machado et al. (1997), baseada no modelo biológico de Chapman-Richards, obtidos com o mesmo conjunto de dados do presente trabalho. Para esta classificação foi utilizada a idade de referência de 7 anos. A equação selecionada por esses autores foi: $h_{d o m}=21$ $\left(\exp (0,08325148(I))^{0,58797742}\right.$, onde: $h_{\text {dom }}-$ altura dominante $(\mathrm{m})$;

Esta equação foi rearranjada por Tonon (1998) para três classes de sítio, com índices de sítio 16,8 m (sítio I), 13,5 m (sítio II) e 10,2 m (sítio III) para a idade índice de 7 anos.

Baseado nesta classificação, um bloco das parcelas permanentes situou-se na classe I, dois blocos situaram-se na classe II e os outros dois na classe III. Para as 124 parcelas temporárias, 20 situaram-se na classe de sítio I, 72 na classe II e 32 na classe III.

\section{Base de dados}

Os dados de campo de cada parcela, permanentes ou temporárias, foram armazenados em arquivos para cada combinação de sítio, idade e densidade. Os dados das parcelas que apresentaram a mesma classificação de sítio, idade e mesma densidade inicial foram agrupados. Portanto, os dados do bloco BS foram agrupados com os dados do bloco CC e os do ADR com os do BDR, formando três blocos correspondentes às três classes de sítio. O mesmo procedimento foi efetuado com as parcelas temporárias. As variáveis, diâmetro à altura do peito $(d)$, altura total $(h)$ e densidade $(N)$ foram obtidas no campo; a altura dominante $\left(h_{d o m}\right)$ foi calculada através da média das alturas das três árvores de maior $(d)$ em uma área de $325 \mathrm{~m}^{2}$ (método das 100 árvores de maior (d) por hectare). $\mathrm{O}$ diâmetro médio quadrático $\left(d_{g}\right)$, que corresponde ao diâmetro da árvore de área seccional média da população, foi obtido pela fórmula $\sqrt{\frac{4 \bar{g}}{\pi}}$.

\section{Modelos testados}

Foram testados 19 modelos matemáticos selecionados da literatura para cada combinação de sítio, idade e densidade, utilizando o método dos mínimos quadrados da análise de regressão linear e o método Quasi- 
Newton para a análise de regressão não linear múltipla. A estimativa dos parâmetros para o ajuste dos modelos foi feita através do pacote estatístico STATISTICA 5.1 do laboratório de processamento de dados do Curso de Pósgraduação em Engenharia Florestal da Universidade Federal do Paraná.

Primeiramente, foram testados 12 modelos (tab. 2), incluindo como variáveis independentes, o diâmetro à altura do peito $(d) \mathrm{e}$ algumas transformações do mesmo. Estes modelos foram testados para as parcelas permanentes em suas várias combinações de sítio, idade e densidade. $\mathrm{O}$ mesmo procedimento foi efetuado para as diversas combinações de sítio e idade das parcelas temporárias

Tabela 2: Modelos tradicionais testados para a estimativa da altura total

Table 2: $\quad$ Traditional Models tested to estimate total height

\begin{tabular}{c|c|c}
\hline & Modelos & Autor \\
\hline \hline & $h=b_{0}+b_{1} \ln (\mathrm{d})$ & Henricksen (1950) \\
3 & $h=b_{0}+b_{1}\left(\mathrm{~d}^{2}\right)$ & $*$ \\
4 & $h=b_{0}+b_{1}(\mathrm{~d})+b_{2}\left(\mathrm{~d}^{2}\right)$ & Trorey (1932) \\
5 & $h=b_{0}+b_{1}(1 / \mathrm{d})$ & Curtis (1967) \\
6 & $h=b_{0}+b_{1}(1 / \mathrm{d})+b_{2}\left(1 / \mathrm{d}^{2}\right)$ & $*$ \\
7 & $\left(d^{2} / h\right)=b_{0}+b_{1}(d)+b_{2}\left(d^{2}\right)$ & Prodan (1965) \\
8 & $\ln h=b_{0}+b_{1} \ln (\mathrm{d})$ & Stoffels (1953) \\
9 & $\ln \mathrm{h}=b_{0}+b_{1}(\mathrm{~d} 2)$ & $*$ \\
10 & $\ln h=b_{0}+b_{1}(\mathrm{~d})+b_{2}\left(\mathrm{~d}^{2}\right)$ & $*$ \\
11 & $\ln h=b_{0}+b_{1}(1 / \mathrm{d})$ & Curtis $(1967)$ \\
\end{tabular}

Legenda: * modelos citados nas seguintes fontes: Curtis (1967); Machado et al. (1993, 1994); Pizatto (1999) e Azevedo et al. (1999)

Além dos modelos tradicionais foram testados sete modelos ditos genéricos para o ajuste da relação hipsométrica, os quais envolvem variáveis do povoamento, referentes aos dados das parcelas temporárias.

Foram testados modelos que incluem, além da variável diâmetro, as variáveis idade $(I)$, densidade $(N)$, diâmetro médio quadrático $\left(d_{g}\right)$ e altura dominante $\left(h_{d o m}\right)$, em suas diversas transformações, como variáveis independentes, tanto em modelos aritméticos, logarítmicos e não lineares (tab. 3)

Tabela 3: Modelos genéricos testados para a estimativa da altura total

Table 3: Generic models tested to estimate total height

\begin{tabular}{c|c|c}
\hline & Modelos & Autor \\
\hline \hline 13 & $\ln h=b_{0}+b_{1}(1 / \mathrm{d})+b_{2}(1 / I)+b_{3}(1 / d . I)$ & Curtis (1967) \\
14 & $\left(d^{2} /(h-1,3)\right)=b_{0}+b_{1}(\mathrm{~d})+b_{2}\left(\mathrm{~d}^{2}\right)+b_{3}(d . I)$ & Blanco-Jorge (1983) \\
15 & $\ln h=b_{0}+b_{1} \mathrm{~h}_{\mathrm{dom}}+b_{2} \ln \left(d_{g} / d\right)+b_{3}(I / d . I)+b_{4}(1 / d)$ & Scolforo (1993) \\
16 & $\ln h=b_{0}+b_{1} \mathrm{~h}_{\mathrm{dom}}+b_{2}(1 / d)+b_{3} \ln (N / d . I)+b_{4}(1 / d . I)$ & Scolforo (1993) \\
17 & $\ln h=b_{0}+b_{1} \mathrm{~S}+b_{2} N+b_{3}(1 / I)+b_{4}(1 / d)$ & (1993) \\
18 & $\ln h=b_{0}+b_{1} \ln \left(\mathrm{h}_{\mathrm{dom}}\right)+b_{2} \cdot(1 / I)+b_{3} \ln (N . \mathrm{d})+b_{4}(1 / d . I)$ & Lenhart (1986) \\
19 & $h=b_{0}+b_{1}(\mathrm{~d})+b_{2}\left(\mathrm{~d}^{2}\right)+b_{3}\left(d . h_{d o m}\right)$ & Embrapa (1988) \\
\hline
\end{tabular}




\section{Escolha do melhor modelo de ajuste}

Para selecionar o melhor modelo de ajuste, foram usadas as estatísticas: índice de ajuste de Schlaegel, erro padrão da estimativa em porcentagem e análise gráfica de resíduos.

Índice de ajuste de Schlaegel (I.A.) é uma estatística comparável ao coeficiente de determinação. Consiste em retransformar as predições dos valores estimados para as unidades originais. No caso de equações aritméticas o valor do índice de Schlaegel é igual ao valor do coeficiente de determinação, não requerendo maiores cálculos. No entanto, para as equações ponderadas ou logaritimizadas, deve-se recorrer ao cálculo do I.A., pois este será diferente do $\mathrm{R}^{2}$. Portanto, este índice serve como um comparador de equações de diversas naturezas:

$$
I . A .=1-\frac{n-1}{n-p} \frac{S Q_{\text {resíduo }}}{S Q_{\text {total }}}
$$

onde:

$S Q=$ soma de quadrados, recalculado para a variável altura total $(h)$

$n=\mathrm{n}^{\mathrm{o}}$ de observações

$p=\mathrm{n}^{\mathrm{o}}$ de variáveis independentes ou $\mathrm{n}^{\mathrm{o}} \mathrm{de}$ coeficientes

Foi necessário recalcular o erro padrão da estimativa $\left(S_{\mathrm{yx}}\right)$ para as equações 6 a 19 , para que se tivesse a mesma base de comparação de $(h)$, como segue:

$$
\begin{gathered}
S_{y x_{\text {recalculado }}}=\sqrt{\frac{\sum(\hat{y}-y)^{2}}{n-p}} \\
S_{y x_{\text {recalculado }}} \%=\frac{S_{y x_{\text {recalculado }}}}{\bar{y}} .100
\end{gathered}
$$

onde:

$$
\begin{array}{ll}
\hat{y}= & \text { ltura estimada } \\
y= & \text { ltura observada } \\
\mathrm{n}= & { }^{\circ} \text { de observações, } \\
\mathrm{p}= & { }^{\circ} \text { de coeficientes, } \\
\overline{\mathrm{y}}= & \text { média aritmética das alturas }
\end{array}
$$

Mesmo que todos os indicadores de ajuste sejam satisfatórios para a escolha do melhor modelo, a análise gráfica dos resíduos é decisiva, pois permite detectar tendenciosidades, emprego inadequado do modelo, baixa correlação entre as variáveis, falta de ajuste e permitindo a tomada de decisão quanto à mudança do modelo ou de sua manutenção.

Como um mesmo modelo raramente é o melhor para todos os casos, procedeu-se um ordenamento entre os 12 modelos tradicionais, para as combinações dos três sítios, quatro medições, quatro densidades das parcelas permanentes e entre os sete modelos genéricos nos três sítios e 15 idades das parcelas temporárias. O objetivo do ordenamento é saber qual modelo de relação hipsométrica que, na média de todas as análises, teve a melhor performance. Cada equação recebeu uma classificação (pontuação) quanto ao melhor ajuste em relação as estatísticas índice de Schlaegel (I.A.) e erro padrão da estimativa em porcentagem $\left(\mathrm{S}_{\mathrm{yx}} \%\right)$. Após a classificação individual, foi feita a soma desta pontuação e o modelo que recebeu o menor valor foi recomendado como o mais adequado para o uso.

\section{RESULTADOS E DISCUSSÕES}

\section{Parcelas permanentes}

A existência de dados em vários sítios, idades e densidades permitiu realizar 480 análises envolvendo a combinação dos modelos matemáticos de 1 a 12 (tab. 02), três classes de sítios (índices de sítio: 16,8 m; 13,5 $\mathrm{m}$ e 10,2 m), idades de quatro a sete anos e quatro tratamentos de densidade inicial (testemunha, 2000, 4000 e 8000 árvores/hectare). Pode-se observar na Tabela 04 os coeficientes estimados para alguns modelos de melhor ajuste e para algumas combinações de sítio, idade e densidades iniciais.

Com base nestas 480 análises pôdese montar uma tabela para comparação entre os modelos testados através das estatísticas índice de Ajuste de Schlaegel (I.A.) e erro padrão da estimativa recalculado em porcentagem $\left(\mathrm{S}_{\mathrm{yx}} \%\right)$ conforme o exemplo apresentado na Tabela 05 para as idades 6,3 e 7,5 anos que são as mais próximas à idade de rotação da espécie e para o sítio II que é a classe intermediária e mais freqüente. No trabalho de Bartoszeck (2000) são encontrados resultados, semelhantes aos das tabelas 4 e 5, para todas as combinações possíveis de idades, sítios e densidades.

Pôde-se verificar uma amplitude grande entre os valores mínimos e máximos 
destas estatísticas. Os menores valores do I.A. e maiores valores de $\mathrm{S}_{\mathrm{yx}} \%$ foram encontrados para os modelos 2 e 8 . Os resultados evidenciaram que nenhum dos modelos testados foi sempre o mais eficiente para todas as combinações, porém os modelos 5, 6 e 11 se destacaram.

As análises realizadas para o ajuste dos modelos de relação hipsométrica forneceram resultados do índice de Schlaegel (I.A.) de 0,16 a 0,94 , apresentando um valor médio de 0,54 e erro padrão da estimativa recalculado em porcentagem $\left(\mathrm{S}_{\mathrm{yx}} \%\right)$ de 5,67 a $19,64 \%$ com um valor médio de $9,11 \%$. Para selecionar um modelo que, na média de todas as análises, obteve a melhor performance, adotou-se um ordenamento entre os mesmos e, para se fazer este ordenamento cada equação foi pontuada de 1 a 12 . O somatório da pontuação das equações para os diferentes sítios, densidades e idades para as parcelas permanentes, segundo as estatísticas índice de Schlaegel e erro padrão da estimativa em porcentagem é apresentado na tabela 6. As menores somas ficaram com os modelos 5,6 e 11 (valores destacados em negrito na tabela 6).

Por outro lado, como a avaliação final foi feita levando-se em consideração não somente as estatísticas I.A. e $\mathrm{S}_{\mathrm{yx}} \%$ mas também uma análise gráfica de resíduos, pôdese observar que os modelos com menor pontuação, algumas vezes, apresentavam tendenciosidades ao longo da linha média, indicando que a pontuação através de estatísticas muitas vezes não é um fator decisivo na escolha de um modelo.

À exceção dos modelos 2,8 e 12 que apresentaram alta tendenciosidade ao longo da linha média, os resíduos para os outros modelos foram bem distribuídos ao longo da linha de regressão ou com pouca tendenciosidade.

Posteriormente, procedeu-se a construção das curvas hipsométricas com o modelo que apareceu em $1^{\circ}$ lugar na soma da pontuação (modelo 5). No entanto, verificou-se uma evolução com tendências anormais nas menores classes de diâmetro para algumas parcelas (fig. 1). O mesmo aconteceu com as curvas traçadas com os modelos 6 e 11 (fig. 2 e 3). Decidiu-se então testar cada modelo até encontrar aquele que apresentasse curvas sem tendenciosidade pois, para as análises futuras de comparação entre as curvas, este comportamento não é o ideal. Chegou-se, enfim, ao modelo 10 (Curtis), o qual não foi o melhor na classificação, mas apresentou estimativas razoáveis da altura total e pela análises de resíduos apresentou uma boa distribuição (fig. 5). A seleção de alguns gráficos mostrados nas figuras 1, 2 e 3, serviram para demonstrar a não adequabilidade dos modelos 5, 6 e 11 para a estimativa da altura total. Como pode ser observado nestas figuras, as curvas se cruzam eventualmente e se dobram para cima. Isto, provavelmente, ocorre devido ao uso de transformação da variável dependente, ou então ao uso de termos ao quadrado nas variáveis independentes. 
Tabela 4: Estimativas dos coeficientes dos modelos de relação hipsométrica que mais se destacaram, para as várias combinações de sítio, idade e densidade inicial das parcelas permanentes

Table 4: $\quad$ Estimates of the coefficients of the best height-diameter relationship model for various combinations of site, age and initial density for the permanent plots

\begin{tabular}{|c|c|c|c|c|c|c|c|c|c|c|c|c|c|}
\hline \multirow{3}{*}{ Sítio } & \multirow{3}{*}{$\begin{array}{l}\text { Idade } \\
\text { (anos) }\end{array}$} & \multirow{3}{*}{$\begin{array}{c}\text { Densidade } \\
\text { (no árv. } \\
\text { /ha) }\end{array}$} & \multicolumn{3}{|c|}{ Modelo 5} & \multicolumn{3}{|c|}{ Modelo 6} & \multicolumn{3}{|c|}{ Modelo 11} & \multicolumn{2}{|c|}{ Modelo 10} \\
\hline & & & \multicolumn{11}{|c|}{ Coeficientes } \\
\hline & & & $b_{0}$ & $b_{1}$ & $b_{2}$ & $b_{0}$ & $b_{1}$ & $b_{2}$ & $b_{0}$ & $b_{1}$ & $b_{2}$ & $b_{0}$ & $b_{1}$ \\
\hline I & 3,9 & testemunha & 17,4540 & $-46,7002$ & 45,5629 & 0,3586 & 0,1331 & 0,0592 & 2,9819 & $-4,0516$ & 2,8181 & 2,8254 & $-2,6242$ \\
\hline I & 3,9 & 2.000 & 13,1459 & $-11,7705$ & $-37,1165$ & 1,6132 & $-0,2283$ & 0,0926 & 2,5180 & 0,1432 & $-8,3542$ & 2,7660 & $-3,1275$ \\
\hline I & 3,9 & 4.000 & 13,8033 & $-6,4353$ & $-51,5989$ & 1,3147 & $-0,2218$ & 0,0886 & 2,5447 & 0,8280 & $-9,3361$ & 2,8416 & $-2,7458$ \\
\hline I & 3,9 & 8.000 & 16,7615 & $-43,2088$ & 39,9699 & 0,4200 & 0,1164 & 0,0624 & 2,9055 & $-3,6416$ & 2,1782 & 2,8041 & $-2,6235$ \\
\hline I & 4,8 & testemunha & 20,5347 & $-81,7177$ & 137,6529 & $-0,4735$ &, 4354 & 0,0337 & 3,2047 & $-6,8615$ & 10,7980 & 2,8848 & $-2,9822$ \\
\hline I & 4,8 & 2.000 & 15,0999 & $-27,9167$ & 9,0639 & 0,5072 & 0,0641 & 0,0691 & 2,7148 & $-1,8354$ & -1, & 2,7616 & $-2,4824$ \\
\hline I & 4,8 & 4.000 & 15,9150 & $-21,9486$ & $-6,7564$ & 0,6231 & $-0,0241$ & 0,0694 & 2,7614 & $-1,1630$ & $-3,1$ & 2,8455 & $-2,2734$ \\
\hline I & 4,8 & 8.000 & 16 , & $-25,6818$ & $-26,6$ & 35 & $-0,0379$ & 0,0695 & 2,7188 & $-0,6299$ & $-7,9037$ & 2,8971 & $-3,0988$ \\
\hline II & 4,1 & testemunha & 11,7890 & $-17,1914$ & 8,6238 & 0,2376 & 0,0823 & 0,0886 & 2,4925 & $-1,7194$ & 0,1911 & 2,4783 & $-1,6033$ \\
\hline II & 4,1 & 2.000 & 12,0704 & $-14,9864$ & $-0,4774$ & 0,6666 & $-0,0411$ & 0,0925 & 2,4914 & $-1,1881$ & $-1,5103$ & 2,5584 & $-1,9230$ \\
\hline II & 4,1 & 4.000 & 13,0809 & $-23,8094$ & 11,4263 & 0,3837 & 0,1047 & 0,0781 & 2,5519 & $-1,6153$ & $-1,4808$ & 2,6156 & $-2,2934$ \\
\hline II & 4,1 & 8.000 & 12,3151 & $-19,4663$ & 7,8554 & 0,4059 & 0,0565 & 0,0865 & 2,5225 & $-1,6909$ & -0 & 2,5510 & $-1,9757$ \\
\hline II & 5,0 & testemunha & 12,3074 & $-16,6855$ & 7,6127 & 0,1694 & 0,0921 & 0,0825 & 2,5141 & $-1,4380$ & -0 , & 2,5198 & $-1,4974$ \\
\hline II & 5,0 & 2.000 & 11,5592 & 2,2862 & $-65,2428$ & 1,0671 & $-0,1395$ & 0,0930 & 2,3944 & 1,1213 & $-9,7661$ & 2,6309 & $-2,0851$ \\
\hline II & 5,0 & 4.000 & 13 & -24, & 67 & 00 & 0,0644 & 0773 & 19 & 913 & -0 & 2 , & $-2,1830$ \\
\hline II & 5,0 & 8.000 & 11,7163 & $-7,5397$ & $-25,5859$ & 0,5358 & $-0,0016$ & 0,0881 & 2,4225 & $-0,0558$ & -4, & 2,5 & $-1,7328$ \\
\hline II & 6,3 & testemunha & 12,9399 & $-17,3008$ & 0,1809 & 0,4455 & 0,0270 & 0,0822 & 2,5579 & $-1,2817$ & $-1,4303$ & 2,6053 & $-1,8434$ \\
\hline II & 6,3 & 2.000 & 13,5609 & $-14,7844$ & $-38,6748$ & 0,7757 & 0,0110 & 0,0766 & 2,5609 & $-0,1973$ & $-8,3250$ & 2,6907 & $-2,3408$ \\
\hline II & 6,3 & 4.000 & 14 & $-34,8$ & 33,3 & 0,2488 & 0,1536 & 0,0673 & 07 & $-2,5376$ & 42 & 2,7021 & $-2,4092$ \\
\hline II & 6,3 & 8.000 & 12,8754 & $-9,7297$ & $-38,2633$ & 0,7235 & $-0,0181$ & 0,0813 & 2,5289 & $-0,2680$ & -5, & 2,6497 & $-2,0521$ \\
\hline II & 7,5 & testemunha & 16,7447 & $-55,2287$ & 53,4134 & 1,5129 & $-0,0100$ & 0,0707 & 2,8724 & $-4,1776$ & 0,2342 & 2,8671 & $-4,1027$ \\
\hline II & 7,5 & 2.000 & 21,5257 & $-158,8275$ & 611,7438 & $-3,5535$ & 0,9481 & 0,0257 & 3,2312 & $-12,5583$ & 48,4039 & 2,7110 & $-2,2857$ \\
\hline II & 7,5 & 4.000 & 15,8539 & $-14,5906$ & $-188,1782$ & 1,7077 & $-0,0009$ & 0,0634 & 2,6628 & 1,5464 & $-29,6293$ & 2,9424 & $-4,3507$ \\
\hline II & 7,5 & 8.000 & 18,0818 & $-71,2595$ & 135,3793 & $-0,4129$ & 0,3828 & 0,0473 & 2,9280 & $-4,8852$ & 10 & 2,8344 & $-3,2634$ \\
\hline III & 4,2 & testemunha & 10,7574 & $-14,4307$ & 7,8182 & 0,0169 & 0,1762 & 0,0866 & 2,4305 & $-1,8035$ & 0,7130 & 2,3215 & $-1,1772$ \\
\hline III & 4,2 & 2.000 & 11,6069 & $-39,5511$ & 75,6509 & $-1,1494$ & 0,6254 & 0,0676 & 2,5314 & $-4,9735$ & 9,2454 & 2,2273 & $-1,3392$ \\
\hline III & 4,2 & 4.000 & 10,2346 & $-16,3055$ & 9,2955 & 0,1708 & 0,1659 & 0,0964 & 2,3482 & $-1,9078$ & 0, & 2,3107 & $-1,6071$ \\
\hline III & 4,2 & 8.000 & 9,7139 & $-11,9268$ & 5,0727 & 0,1692 & 0,1014 & 0,1057 & 2,3252 & $-1,6474$ & 0,4199 & 2,2620 & $-1,2583$ \\
\hline III & 5,4 & testemunha & 12,0152 & $-15,2964$ & 5,4274 & 0,2599 & 0,0465 & 0,0889 & 2,5019 & $-1,3975$ & $-0,2297$ & 2,5191 & $-1,5338$ \\
\hline III & 5,4 & 2.000 & 12,4227 & $-33,8008$ & 38,5302 & 0,1169 & 0,2857 & 0,0763 & 2,5142 & $-2,7572$ & 0,1226 & 2,5120 & $-2,7233$ \\
\hline III & 5,4 & 4.000 & 11,6982 & $-16,4898$ & 7,4088 & 0,1960 & 0,1026 & 0,0866 & 2,4589 & $-1,4205$ & $-0,4027$ & 2,4741 & $-1,5897$ \\
\hline III & 5,4 & 8.000 & 11,2880 & $-14,9536$ & 7,0082 & 0,1776 & 0,0926 & 0,0908 & 2,4369 & $-1,4679$ & 0,0573 & 2,4335 & $-1,4380$ \\
\hline III & 6,3 & testemunha & 12,5878 & $-18,5509$ & 6,9433 & 0,2549 & 0,0903 & 0,0810 & 2,5251 & $-1,3907$ & $-0,8602$ & 2,5664 & $-1,7927$ \\
\hline III & 6,3 & 2.000 & 12,5668 & $-28,7848$ & 2,8439 & 1,1771 & 0,0598 & 0,0851 & 2,5246 & $-2,1294$ & $-4,1209$ & 2,5864 & $-3,1670$ \\
\hline III & 6,3 & 4.000 & 12,0332 & $-13,8239$ & $-10,8618$ & 0,6702 & $-0,0128$ & 0,0895 & 2,4621 & $-0,7426$ & $-3,4856$ & 2,5619 & $-2,0054$ \\
\hline III & 6,3 & 8.000 & 11,7659 & $-18,0361$ & 10,2321 & 0,2036 & 0,1098 & 0,0866 & 2,4580 & $-1,4718$ & $-0,4542$ & 2,4745 & $-1,6511$ \\
\hline III & 7,6 & testemunha & 18,6161 & $-85,9287$ & 135,7762 & 0,2340 & 0,4700 & 0,0387 & 3,2297 & $-9,2963$ & 13,6487 & 2,7693 & $-3,9798$ \\
\hline III & 7,6 & 2.000 & 17,6009 & $-107,9942$ & 311,4961 & $-2,2060$ & 0,8971 & 0,0334 & 2,9533 & $-8,8035$ & 21,7155 & 2,7094 & $-4,1281$ \\
\hline III & 7,6 & 4.000 & 17,0617 & $-65,1497$ & 80,0288 & 2,2151 & $-0,1187$ & 0,0776 & 2,9402 & $-5,4510$ & 3,2046 & 2,8639 & $-4,3977$ \\
\hline III & 7,6 & 8.000 & 18,7089 & $-93,6355$ & 161,8168 & $-0,6887$ & 0,8178 & 0,0147 & 3,2991 & $-10,5910$ & 17,1486 & 2,7510 & $-4,2088$ \\
\hline
\end{tabular}


Tabela 5: Estatísticas de ajuste para os diversos modelos de relação hipsométrica testados para as idades 6,3 e 7,5 anos, para os quatro tratamentos de densidade inicial no sítio II

Table 5: $\quad$ Fitting statistics for the several height-diameter relationship models tested for ages 6.3 and 7.5 years involving the four initial density measurements at site II

\begin{tabular}{|c|c|c|c|c|c|c|c|c|c|c|c|c|c|c|c|c|}
\hline \multirow{3}{*}{ Equação } & \multicolumn{8}{|c|}{6,3 (anos) } & \multicolumn{8}{|c|}{ 7,5 (anos) } \\
\hline & \multicolumn{2}{|c|}{ Testemunha } & \multicolumn{2}{|c|}{$\begin{array}{c}2.000 \\
\text { árv./ha }\end{array}$} & \multicolumn{2}{|c|}{$\begin{array}{l}4.000 \\
\text { árv./ha }\end{array}$} & \multicolumn{2}{|c|}{$\begin{array}{c}8.000 \\
\text { árv./ha }\end{array}$} & \multicolumn{2}{|c|}{ Testemunha } & \multicolumn{2}{|c|}{$\begin{array}{l}2.000 \\
\text { árv./ha }\end{array}$} & \multicolumn{2}{|c|}{$\begin{array}{c}4.000 \\
\text { árv./ha }\end{array}$} & \multicolumn{2}{|c|}{$\begin{array}{c}8.000 \\
\text { árv./ha }\end{array}$} \\
\hline & I.A. & $S_{y x} \%$ & I.A. & $S_{y x} \%$ & I.A. & $\mathrm{S}_{\mathrm{yx}} \%$ & I.A. & $S_{y x} \%$ & I.A. & $\mathrm{S}_{\mathrm{yx}} \%$ & I.A. & $\mathrm{S}_{\mathrm{yx}} \%$ & I.A. & $\mathrm{S}_{\mathrm{yx}} \%$ & I.A. & $S_{\mathrm{yx}} \%$ \\
\hline 1 & ,602 & 8,061 & 0,374 & 7,186 & 1 & 6,851 & $0,511 \mid$ & 7,169 & 0,566 & $1 J, 0 J 0$ & 0,191 & 10,688 & 0,337 & \begin{tabular}{l|l}
71,548 \\
\end{tabular} & 0,453 & \begin{tabular}{l|l}
39,515 \\
\end{tabular} \\
\hline 2 & 416 & 9,765 & 80 & 7,7 & 0,470 & 7 , & 0,397 & 7,964 & 38 & 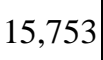 & 0,223 & 10,472 & 0,309 & 11,788 & 0,429 & 99,720 \\
\hline 3 & 0,624 & 7,837 & 0,405 & 7,004 & 0,569 & 6,865 & 0,520 & 7,105 & 0,569 & 13,7 & 0,197 & 70,647 & 0,323 & 11,67 & 0,441 & 19,616 \\
\hline 4 & 0,643 & 7,640 & 0,391 & 7,087 & 0,576 & 6,812 & $0,538 \mid$ & 6,967 & 0,574 & 13,70 & 0,162 & $\mid 10,876$ & 0,343 & 11,493 & 0,439 & 99,636 \\
\hline 5 & 0,641 & 7,661 & 0,394 & 7,067 & 0,576 & 6,808 & 0,539 & 6,961 & 0,572 & 13,74 & $\mid 0,198$ & 10,643 & 0,334 & 11,57 & 0,439 & $\begin{array}{l}99,633 \\
\end{array}$ \\
\hline 6 & 0,643 & 7,635 & 0,389 & | & 0 & 08 & 538 & 6,972 &, 574 & 13,71 & 0,200 & 10,627 & 0,330 & 11,60 & 0,442 & 29,606 \\
\hline 7 & 0,575 & 8,330 & 0,363 & 7,2 & 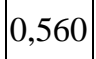 & 6,942 & 0,498 & 7,263 & 0,534 & 14,3 & 196 & 10,652 & 0,332 & 11, & 0,453 & 39,513 \\
\hline 8 & 0,384 & 10,030 & 0,259 & 7,817 & 0,447 & 7,781 & 0,374 & 8,110 & 0,375 & 16,607 & 0,222 & 10,478 & 0,299 & 11,876 & 0,418 & 89,812 \\
\hline 9 & 0,610 & 7,984 & 0,406 & 6 & 0 & 6, & 513 & 7,155 & 56 & 14,00 & 0,194 & 10,668 & 0,318 & 11,711 & 0,438 & $\begin{array}{l}89,647 \\
\end{array}$ \\
\hline 10 & 0,637 & 7,700 & 0,389 & 7 & . & $t_{-1}$ & 532 & 7,012 & 0,577 & 13,662 & 0,167 & 710,841 & 0,340 & 11,52 & 0,44 & 69,576 \\
\hline 11 & 0,641 & 7,657 & 0,389 & 7,097 & 0,576 & 6,810 & 0,538 & 6,965 & 0,570 & 13,782 & 0,167 & 710,841 & 0,331 & 11,601 & 0,441 & 19,620 \\
\hline 12 & 0,514 & 8,912 & 0,334 & 7,409 & 0,530 & 7,175 & 0,461 & 7,527 & 0,512 & 14,674 & $\mid 0,213$ & $\mid 10,540$ & 0,326 & 11,647 & 0,448 & $\begin{array}{l}89,554 \\
\end{array}$ \\
\hline
\end{tabular}

Legenda: I.A. - índice de Ajuste de Schlaegel, $\mathrm{S}_{\mathrm{yx}} \%$ - erro padrão da estimativa em percentual.

Tabela 6: Somatório da pontuação das equações para os diferentes sítios, densidades e idades de medição para as parcelas permanentes, segundo as estatísticas índice de ajuste de Schlaegel e erro padrão da estimativa em percentagem

Table 6: Sum of the equation ranking for the different sites, densities and measurement ages for the permanent plots, according to the Schlaegel fitting index and standard error of estimate in percent

\begin{tabular}{|c|c|c|c|c|c|c|c|c|c|c|c|c|c|c|c|c|c|c|c|c|c|c|c|c|}
\hline \multirow{6}{*}{ 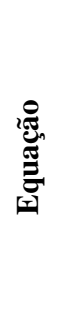 } & \multicolumn{24}{|c|}{ Análise $\mathbf{N}^{\mathbf{0}}$} \\
\hline & 1 & 2 & 3 & 4 & 5 & 6 & 7 & 8 & 9 & 10 & 11 & 12 & 13 & 14 & 15 & 16 & 17 & 18 & 19 & 20 & 21 & 22 & 23 & 2 \\
\hline & \multicolumn{8}{|c|}{ Sitio I } & \multicolumn{16}{|c|}{ Sítio II } \\
\hline & \multicolumn{4}{|c|}{ 3,9 anos } & \multicolumn{4}{|c|}{ 4,8 anos } & \multicolumn{4}{|c|}{ 4,1 anos } & \multicolumn{3}{|c|}{5,0 anos } & & \multicolumn{4}{|c|}{6,3 anos } & \multicolumn{4}{|c|}{ 7,5 anos } \\
\hline & \multicolumn{24}{|c|}{ Tratamentos } \\
\hline & T1 & $\mathbf{T} 2$ & T3 & T4 & T1 & $\mathbf{T 2}$ & T3 & T4 & T1 & $\mathbf{T 2}$ & T3 & T4 & T1 & $\mathbf{T 2}$ & T3 & T4 & T1 & $\mathbf{T} 2$ & T3 & T4 & T1 & $\mathbf{T 2}$ & T3 & \\
\hline 1 & 14 & 16 & 16 & 14 & 11 & 14 & 16 & 15 & 14 & 16 & 12 & 14 & 16 & 12 & 16 & 16 & 16 & 16 & 12 & 16 & 14 & 18 & 12 & \\
\hline 2 & 22 & 22 & 22 & 22 & 20 & 22 & 22 & 22 & 22 & 22 & 22 & 22 & 22 & 16 & 22 & 22 & 22 & 22 & 22 & 22 & 22 & 2 & 33 & 2 \\
\hline 3 & 2 & 8 & 10 & 2 & 7 & 12 & 2 & 11 & 12 & 10 & 14 & 12 & 2 & 9 & 12 & 12 & 12 & 4 & 14 & 12 & 12 & 12 & 25 & \\
\hline 4 & 16 & 10 & 8 & 16 & 22 & 2 & 7 & 2 & 10 & 6 & 10 & 8 & 8 & 6 & 4 & 6 & 4 & 8 & 10 & 8 & 4 & 24 & 4 & 18 \\
\hline 5 & 4 & 6 & 6 & 4 & 3 & 6 & 11 & 4 & 4 & 7 & 2 & 4 & 10 & 2 & 8 & 2 & 8 & 6 & 4 & 2 & 8 & 10 & 9 & \\
\hline 6 & 8 & 2 & 2 & 6 & 13 & 8 & 7 & 8 & 2 & 2 & 6 & 2 & 10 & 10 & 2 & 8 & 2 & 12 & 6 & 6 & 6 & 8 & 18 & \\
\hline 7 & 18 & 18 & 18 & 18 & 8 & 18 & 18 & 18 & 18 & 18 & 18 & 18 & 18 & 19 & 18 & 18 & 18 & 18 & 18 & 18 & 18 & 14 & 18 & \\
\hline 8 & 24 & 24 & 24 & 24 & 24 & 24 & 24 & 24 & 24 & 24 & 24 & 24 & 24 & 24 & 24 & 24 & 24 & 24 & 24 & 24 & 24 & 4 & 36 & 24 \\
\hline 9 & 6 & 12 & 14 & 12 & 4 & 16 & 4 & 15 & 16 & 14 & 16 & 16 & 4 & 16 & 14 & 14 & 14 & 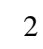 & 16 & 14 & 16 & 16 & 29 & 20 \\
\hline 10 & 10 & 14 & 12 & 8 & 18 & 4 & 14 & 11 & 6 & 12 & 8 & 10 & 8 & 13 & 6 & 10 & 10 & 10 & 2 & 10 & 2 & 20 & 9 & \\
\hline 11 & 12 & 4 & 4 & 10 & 10 & 10 & 11 & 6 & 8 & 5 & 4 & 6 & 14 & 8 & 10 & 4 & 6 & 14 & 8 & 4 & 10 & 22 & 15 & 14 \\
\hline 12 & 20 & 20 & 20 & 20 & 16 & 20 & 20 & 20 & 20 & 20 & 20 & 20 & 20 & 21 & 20 & 20 & 20 & 20 & 20 & 20 & 20 & 6 & 26 & \\
\hline
\end{tabular}

Continua... 
Conclusão da tabela 6

\begin{tabular}{|c|c|c|c|c|c|c|c|c|c|c|c|c|c|c|c|c|c|}
\hline \multirow{6}{*}{$\frac{\frac{0}{0}}{\frac{0}{g}}$} & \multicolumn{16}{|c|}{ Análise $\mathbf{N}^{\circ}$} & \multirow{6}{*}{ 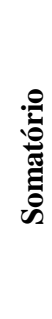 } \\
\hline & 25 & 26 & 27 & 28 & 29 & 30 & 31 & 32 & 33 & 34 & 35 & 36 & 37 & 38 & 39 & 40 & \\
\hline & \multicolumn{16}{|c|}{ Sitio III } & \\
\hline & \multicolumn{4}{|c|}{4,2 anos } & \multicolumn{4}{|c|}{5,4 anos } & \multicolumn{4}{|c|}{6,3 anos } & \multicolumn{4}{|c|}{7,6 anos } & \\
\hline & \multicolumn{16}{|c|}{ Tratamentos } & \\
\hline & T1 & $\mathbf{T} 2$ & T3 & T4 & T1 & $\mathbf{T} 2$ & T3 & T4 & T1 & $\mathbf{T} 2$ & T3 & T4 & T1 & $\mathbf{T} 2$ & T3 & T4 & \\
\hline 1 & 8 & 20 & 14 & 10 & 14 & 2 & 16 & 12 & 12 & 12 & 16 & 16 & 14 & 9 & 14 & 16 & 529 \\
\hline 2 & 22 & 12 & 22 & 22 & 22 & 22 & 22 & 22 & 22 & 22 & 22 & 22 & 22 & 5 & 22 & 18 & 810 \\
\hline 3 & 6 & 16 & 2 & 12 & 12 & 18 & 2 & 14 & 14 & 14 & 10 & 2 & 6 & 13 & 3 & 8 & 382 \\
\hline 4 & 18 & 24 & 16 & 14 & 10 & 6 & 8 & 10 & 10 & 2 & 4 & 6 & 20 & 24 & 16 & 24 & 425 \\
\hline 5 & 2 & 8 & 12 & 3 & 4 & 14 & 12 & 6 & 2 & 10 & 8 & 12 & 2 & 19 & 6 & 4 & 264 \\
\hline 6 & 16 & 2 & 8 & 3 & 2 & 10 & 10 & 4 & 6 & 6 & 2 & 10 & 10 & 10 & 3 & 10 & 274 \\
\hline 7 & 14 & 18 & 18 & 16 & 18 & 8 & 18 & 18 & 18 & 18 & 18 & 18 & 12 & 7 & 18 & 12 & 634 \\
\hline 8 & 24 & 14 & 24 & 24 & 24 & 24 & 24 & 24 & 24 & 24 & 24 & 24 & 24 & 11 & 24 & 22 & 903 \\
\hline 9 & 12 & 10 & 4 & 18 & 16 & 20 & 6 & 16 & 16 & 16 & 14 & 8 & 4 & 14 & 12 & 6 & 498 \\
\hline 10 & 10 & 22 & 6 & 6 & 8 & 4 & 4 & 2 & 8 & 4 & 12 & 4 & 18 & 21 & 8 & 20 & 380 \\
\hline 11 & 4 & 4 & 10 & 8 & 6 & 12 & 14 & 8 & 4 & 8 & 6 & 14 & 8 & 19 & 10 & 2 & 352 \\
\hline 12 & 20 & 6 & 20 & 20 & 20 & 16 & 20 & 20 & 20 & 20 & 20 & 20 & 16 & 4 & 20 & 14 & 711 \\
\hline
\end{tabular}

$\mathrm{T} 1=$ Testemunha; $\mathrm{T} 2=2.000$ árvores/ha $; \mathrm{T} 3=4.000$ árvores/ha; $\mathrm{T} 4=8.000$ árvores $/$ ha

Figura 1: Curvas de relação hipsométrica, em função das densidades iniciais para as idades 4,2 e 7,6 anos no sítio III, estimadas pelo modelo 6

Figure 1: Curves of height-diameter related to initial densities for the ages 4.2 and 7.6 years at site III, estimated by the model 6

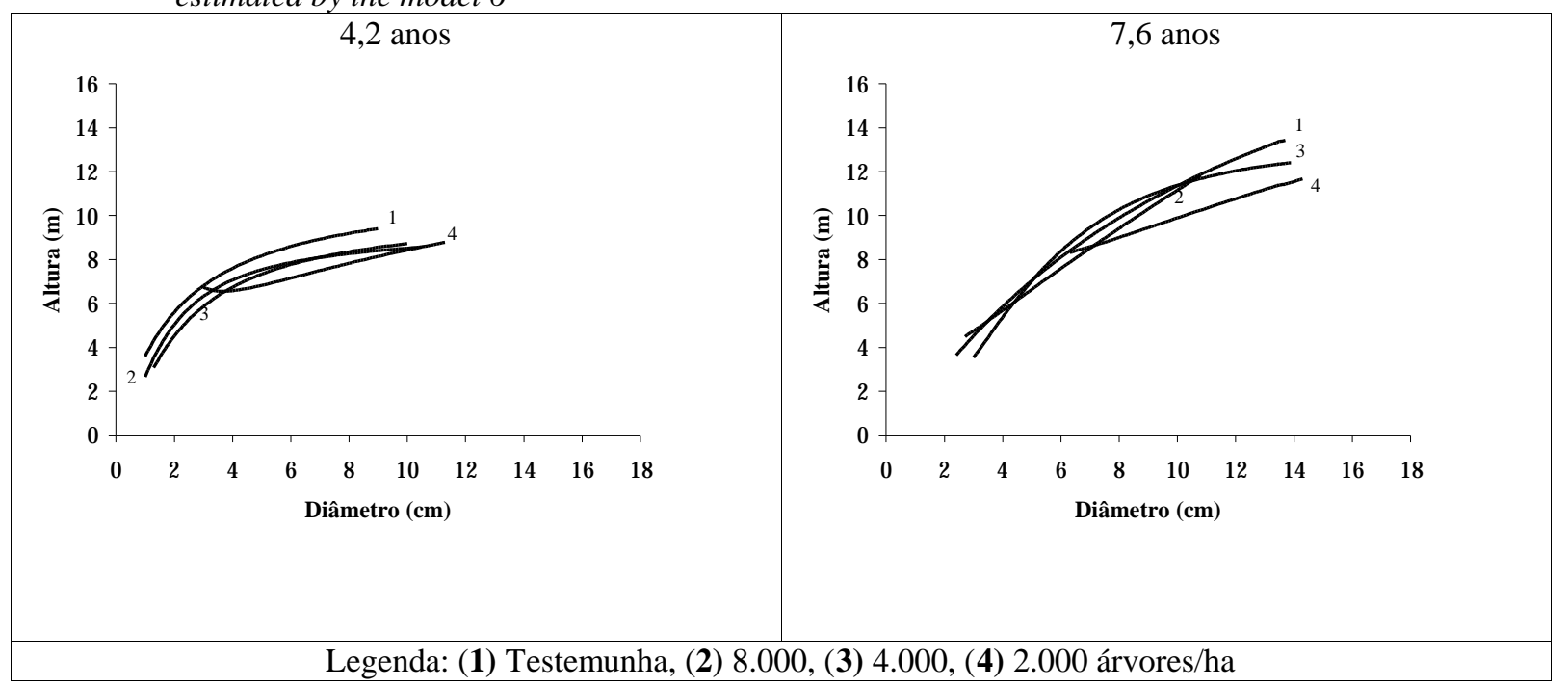


Modelagem da relação hipsométrica...

Figura 2: Curvas de relação hipsométrica, em função das densidades iniciais para as idades 4,2 e 7,6 anos no sítio III, estimadas pelo modelo 5

Figure 2: Curves of height-diameter related to initial densities for the ages 4.2 and 7.6 years at site III, estimated by the model 5

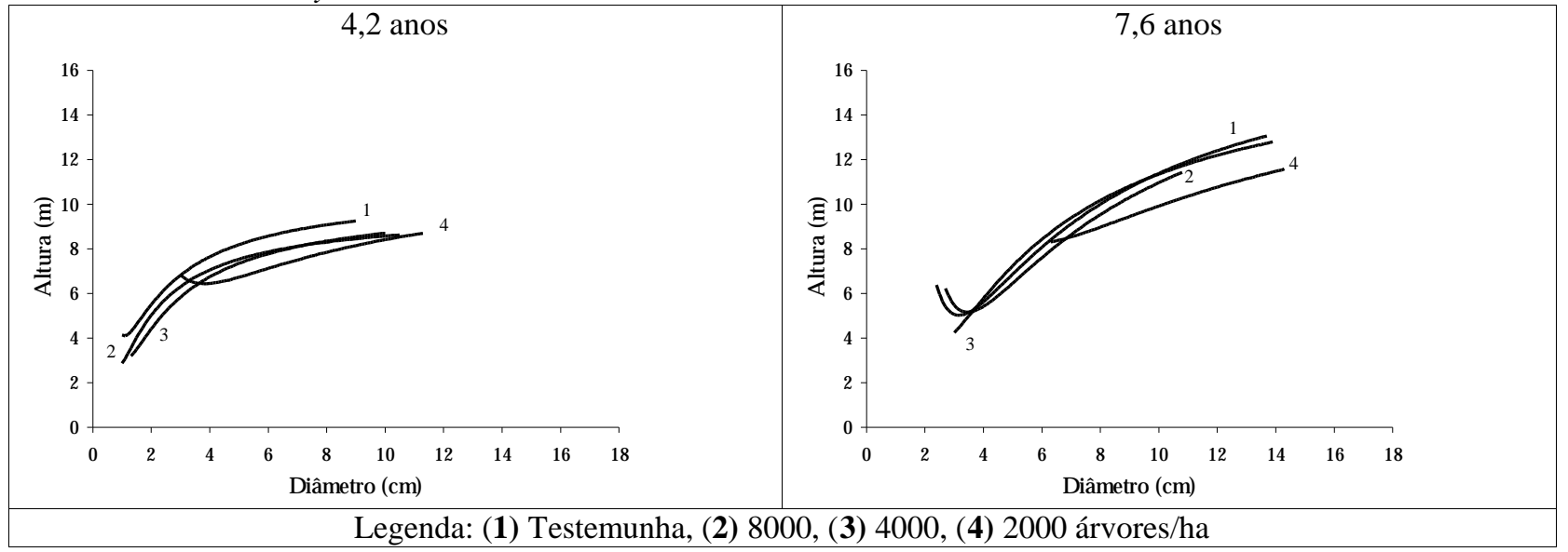

Figura 3: Curvas de relação hipsométrica, em função das densidades iniciais para as idades 4,2 e 7,6 anos no sítio III, estimadas pelo modelo 11

Figure 3: Curves of height-diameter related to initial densities for the ages 4.2 and 7.6 years at site III, estimated by the model 11

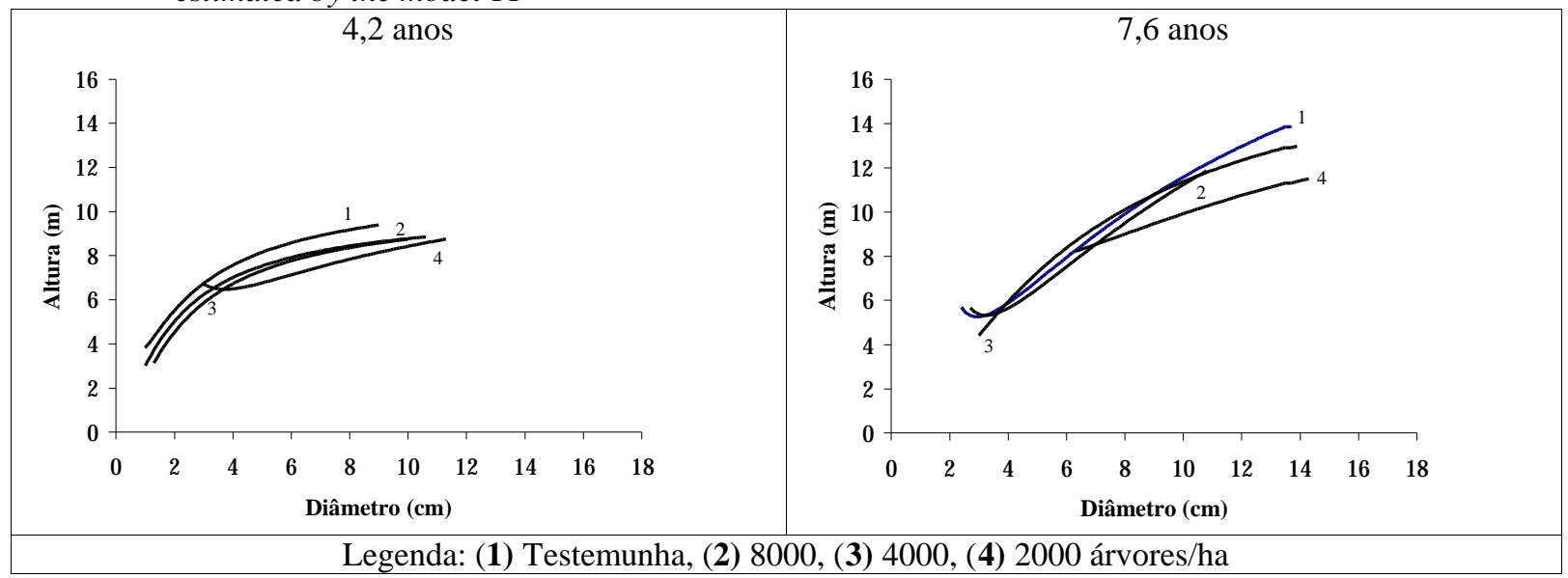

Figura 4: Curvas de relação hipsométrica, em função das densidades iniciais para as idades 4,2 e 7,6 anos no sítio III, estimadas pelo modelo 10

Figure 4: Curves of height-diameter related to initial densities for the ages 4.2 and 7.6 years at site III, estimated by the model 10

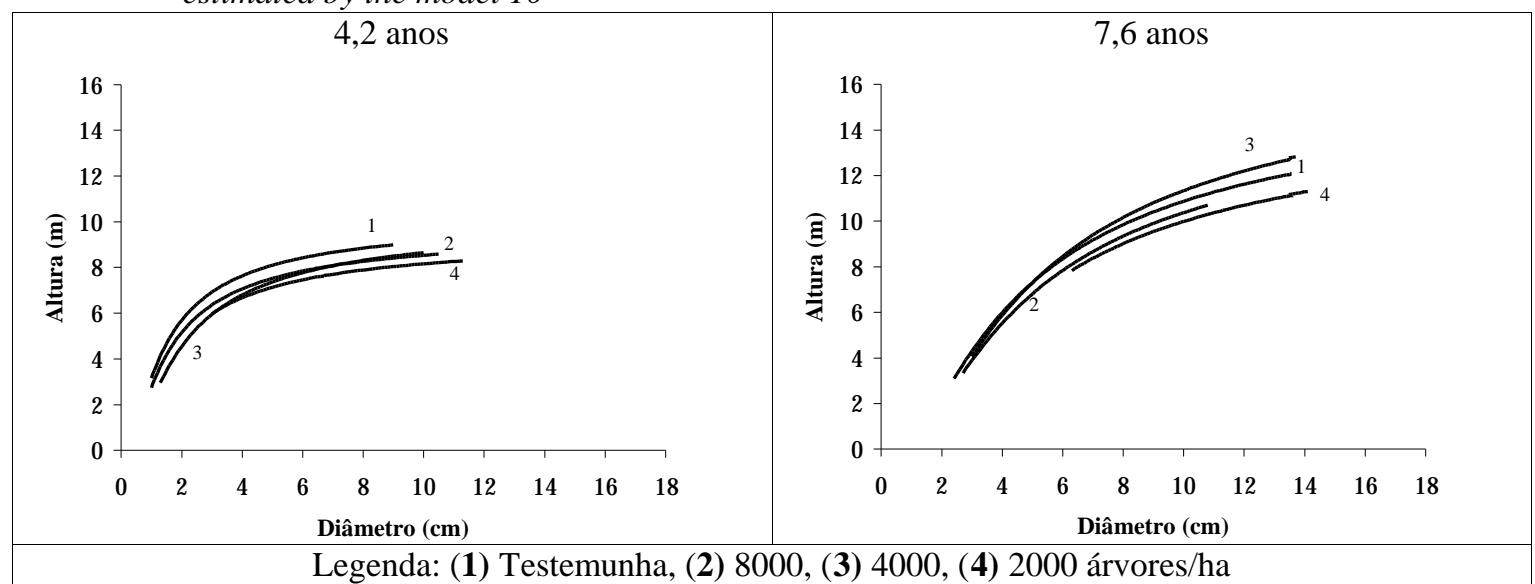




\section{Parcelas temporárias}

As estatísticas para o total dos dados (4.949 árvores) revelaram uma amplitude diamétrica de 3,4 a $33,6 \mathrm{~cm}$, uma média diamétrica de $9,1 \mathrm{~cm}$ e um desvio padrão de $2,6 \mathrm{~cm}$. Com relação à variável altura, encontrou-se uma amplitude de 0,9 a $23 \mathrm{~m}$, uma média de $11,5 \mathrm{~m}$ e um desvio padrão de $3,4 \mathrm{~m}$.

Os dados das parcelas temporárias, também, foram utilizadas para o ajuste dos modelos 1 a 12 contidos na Tabela 02 para a combinação das 124 parcelas, classificadas em três classes de sítios já explicitadas e idades 4 , 5, 6, 9, 10, 11 anos no sítio I; $3,4,5,6,7,8,9$, 11,12 e 18 anos no sítio II; 4, 5, 6, 7, 9, 10 e 12 anos no sítio III, resultando em 264 análises de regressão. As análises realizadas para o ajuste dos modelos forneceram resultados do índice de Schlaegel (I.A.) de 0,061 a 0,805 apresentando um valor médio de 0,407 e erro padrão da estimativa $\left(S_{\mathrm{yx}} \%\right)$ de 5,429 a 18,392 com um valor médio de 11,306 .

$\mathrm{O}$ mesmo procedimento de pontuação dos modelos, através da classificação (ranking) das estatísticas índice de Schlaegel e erro padrão da estimativa em porcentagem, foram efetuadas para estas parcelas e o resultado encontrado foi similar ao das parcelas permanentes, ou seja, a escolha do modelo 10 , como o mais adequado e os piores ajustes com os modelos 2 e 8 . Logo, serviu para confirmar o uso do modelo 10 para a estimativa de alturas e análises estatísticas posteriores.

\section{Modelos Genéricos}

Com o objetivo de se obter um modelo genérico as parcelas temporárias e posteriormente para o agrupamento dessas com as testemunhas das parcelas permanentes, foram testados modelos com variáveis independentes que englobam a idade do povoamento, a densidade, a altura dominante e o diâmetro médio quadrático.

Estas parcelas foram agrupadas de forma que abrangessem todos os sítios, idades e densidades. Os modelos 13 a 19 da Tabela 03, que incluem estas variáveis, foram ajustados, numa primeira etapa, para todas as parcelas temporárias conjuntamente e, numa segunda etapa, para a combinação das testemunhas das parcelas permanentes com as parcelas temporárias, de forma que se pudesse fazer um confronto entre as permanentes e as temporárias e descobrir se haveria um modelo que pudesse ser comum às mesmas.

\section{Correlação linear simples}

Um estudo de correlação linear simples foi efetuado com a finalidade de observar a tendência de associação entre as variáveis dependentes e independentes, as quais serviram para compor um modelo de regressão pelo processo Stepwise que, segundo Draper \& Smith (1966), visa encontrar um modelo mais adequado, através de inclusões sucessivas de variáveis, que aqueles préselecionados da literatura.

$\mathrm{Na}$ tabela 7 pode-se observar a correlação linear simples entre as variáveis dependentes altura total $(h)$ e todas as variáveis independentes envolvidas na pesquisa. As variáveis mais fortemente correlacionadas foram o diâmetro à altura do peito $(d)$ e a altura dominante $\left(h_{d o m}\right)$, nas suas formas simples, logaritmizadas e combinadas. O produto do diâmetro pela altura dominante $\left(h_{d o m} . d\right)$ apareceu em primeiro lugar, seguido da altura dominante $\left(h_{d o m}\right)$ e o logaritmo da altura dominante $\left(\operatorname{Ln}\left(h_{d o m}\right)\right)$. As variáveis mais fortemente correlacionadas estão destacadas em negrito nesta mesma tabela. 
Tabela 7: Correlação simples entre as variáveis dependentes e independentes para o total dos dados das parcelas temporárias e da combinação das parcelas temporárias com as testemunhas das parcelas permanentes

Table 7: $\quad$ Simple correlation among the dependent and independent variables for the total temporary plot data and of the combination of the temporary plots with the control of the permanent plots

\begin{tabular}{|c|c|c|c|c|}
\hline \multirow[b]{2}{*}{ Variáveis } & \multicolumn{2}{|c|}{ Temporárias } & \multicolumn{2}{|c|}{ Temporárias + Permanentes } \\
\hline & $h$ & Lnh & $h$ & Lnh \\
\hline$D$ & 0,78 & 0,75 & 0,69 & 0,65 \\
\hline 1/Idade & $-0,58$ & $-0,56$ & $-0,53$ & $-0,51$ \\
\hline $\operatorname{Ln}\left(h_{d o m}\right)$ & $\mathbf{0 , 8 0}$ & $\mathbf{0 , 7 7}$ & 0,77 & 0,76 \\
\hline $\operatorname{Ln}(N . d)$ & $-0,17$ & $-0,14$ & $-0,02$ & 0,00 \\
\hline $\operatorname{Ln}(d)$ & $-0,67$ & $-0,66$ & $-0,55$ & $-0,51$ \\
\hline $\operatorname{Ln}(N / d)$ & $-0,79$ & $-0,79$ & $-0,72$ & $-0,68$ \\
\hline Ln (Idade) & 0,61 & 0,57 & 0,57 & 0,53 \\
\hline $\operatorname{Ln}\left(h_{\text {dom }} /\right.$ Idade $)$ & $-0,14$ & $-0,12$ & $-0,13$ & $-0,10$ \\
\hline $\operatorname{Ln}(d g / d)$ & $-0,42$ & $-0,46$ & $-0,35$ & $-0,35$ \\
\hline$D g$ & 0,72 & 0,67 & 0,63 & 0,57 \\
\hline$h_{d o m}$ & $\mathbf{0 , 8 1}$ & 0,76 & 0,79 & 0,76 \\
\hline$h_{d o m} . d$ & $\mathbf{0 , 8 5}$ & 0,79 & 0,81 & 0,75 \\
\hline $\operatorname{Ln}(d)$ & 0,79 & 0,81 & 0,71 & 0,68 \\
\hline$(d)^{2}$ & 0,69 & 0,63 & 0,63 & 0,58 \\
\hline $1 / d$ & $-0,69$ & $-0,76$ & $-0,69$ & $-0,67$ \\
\hline $1 /(d)^{2}$ & $-0,51$ & $-0,60$ & $-0,65$ & $-0,64$ \\
\hline (d. Idade) & 0,72 & 0,65 & 0,68 & 0,62 \\
\hline$I$ & 0,61 & 0,55 & 0,57 & 0,52 \\
\hline$S$ & 0,45 & 0,44 & 0,36 & 0,36 \\
\hline$N$ & $-0,59$ & $-0,62$ & $-0,51$ & $-0,50$ \\
\hline
\end{tabular}

Legenda: $d$ - diâmetro à altura do peito, $h$ - altura total, $h_{\text {dom }}$ - altura dominante, $l n$ - logaritmo natural, $N$ densidade, $S$ - sítio, $I$ - idade, $d g$ - diâmetro da área transversal média.

\section{Método de regressão passo a passo}

Todas as variáveis relacionadas na tabela 7 foram inseridas no programa estatístico e através do método regressão passo a passo foram incluídas como variáveis independentes visando compor um modelo de melhor ajuste. Como esperado, quanto mais variáveis fossem incluídas melhor se tornava o ajuste, mas a partir da $4^{\mathrm{a}}$ e $5^{\mathrm{a}}$ variáveis adicionadas ao modelo resultava em ganhos não tão significativos de precisão. Logo, como os modelos préselecionados na literatura apresentavam somente no máximo cinco parâmetros, decidiuse pela escolha de um modelo com cinco parâmetros (tab. 8). Portanto, as variáveis que fizeram parte do modelo corresponderam dentre as mais fortemente correlacionadas, como a altura dominante, tanto na sua forma aritmética como logaritmizada.

Além da altura dominante em sua forma aritmética e logarítmica, o método regressão passo a passo selecionou o diâmetro médio quadrático $\left(d_{g}\right)$ associado ao diâmetro $(d)$. Isoladamente a variável $d_{g}$ tem forte correlação com a altura total, mas a combinação com o diâmetro apresentou correlação baixa. No entanto, dentro do modelo de regressão, serviu para contribuir para um melhor ajuste, devido às interações que a análise de regressão faz para obter a melhor composição de variáveis.

Tabela 8: Modelos genéricos utilizados para a estimativa da altura total obtidos pelo processo regressão passo a passo Table 8: $\quad$ Generic models used to estimate total height obtained by the stepwise process

\begin{tabular}{c|c}
\hline Modelos & Parcelas temporárias \\
\hline \hline 20 & $\ln h=b_{0}+b_{1} \cdot\left(\mathrm{h}_{\mathrm{dom}}\right)+b_{2} \cdot \ln \left(d_{g} / d\right)+b_{3} \cdot \ln (1 / d \cdot I)+b_{4} \cdot N$ \\
\hline 21 & $h=b_{0}+b_{1} \cdot\left(\mathrm{h}_{\mathrm{dom}} \cdot \mathrm{d}\right)+b_{2} \cdot\left(d^{2}\right)+b_{3} \cdot \ln \left(d_{g} / d\right)+b_{4} \cdot \ln h_{d o m}$ \\
\hline \hline \multicolumn{2}{c}{ Parcelas temporárias + testemunhas das permanentes } \\
\hline 22 & $\ln h=b_{0}+b_{1} \cdot \ln (\mathrm{d})+b_{2} \cdot \ln \left(\mathrm{h}_{\mathrm{dom}}\right)+b_{3} \cdot \ln \left(d_{g} / d\right)+b_{4} \cdot(1 / d \cdot I)$ \\
$h=b_{0}+b_{1} \cdot\left(\mathrm{h}_{\mathrm{dom}} \cdot \mathrm{d}\right)+b_{2} \cdot\left(d^{2}\right)+b_{3} \cdot(1 / d)+b_{4} \cdot d_{g}$ \\
\hline
\end{tabular}


Tanto os coeficientes das equações genéricas, como as desenvolvidas por regressão passo a passo são apresentados na tabela 9.

Tabela 9: Estimativas dos coeficientes dos modelos genéricos de relação hipsométrica, para as parcelas temporárias e temporárias em conjunto com as testemunhas das permanentes

Table 9: $\quad$ Estimates of the coefficients of the generic models of height-diameter relationship, for the temporary plots alone and temporary plots together with the control of the permanent plots

\begin{tabular}{|c|c|c|c|c|c|c|c|c|c|c|}
\hline \multirow[t]{3}{*}{ Modelos Genéricos } & \multicolumn{5}{|c|}{ Parcelas temporárias } & \multicolumn{5}{|c|}{$\begin{array}{c}\text { Parcelas temporárias }+ \\
\text { testemunhas das permanentes }\end{array}$} \\
\hline & \multicolumn{10}{|c|}{ Coeficientes } \\
\hline & $b_{0}$ & $b_{1}$ & $b_{2}$ & $b_{3}$ & $b_{4}$ & $b_{0}$ & $b_{1}$ & $b_{2}$ & $b_{3}$ & $b_{4}$ \\
\hline 13 & 3,1423 & $-4,0668$ & $-2,0961$ & 5,5226 & & 3,2178 & $-4,7585$ & $-3,0879$ & 13,4776 & \\
\hline 14 & 0,0864 & 0,5096 & 0,0551 & $-0,0225$ & & $-0,2502$ & 0,5742 & 0,0520 & $-0,0213$ & \\
\hline 15 & 1,7805 & 0,0609 & $-0,2068$ & $-2,5871$ & $-0,6423$ & 1,6652 & 0,0660 & $-0,2304$ & $-1,3390$ & $-0,4650$ \\
\hline 16 & 2,0553 & 0,0520 & $-2,1751$ & $-0,0022$ & $-1,1962$ & 1,9447 & 0,0559 & $-1,8499$ & $-0,0086$ & 1,8544 \\
\hline 17 & 2,5094 & 0,0428 & 0,0000 & $-1,6327$ & $-2,7306$ & 2,3424 & 0,0444 & 0,0000 & $-2,1781$ & $-1,6454$ \\
\hline 18 & 0,7579 & 0,6958 & 1,5509 & $-0,0061$ & $-14,2908$ & $-0,3890$ & 0,8040 & 0,2633 & 0,0845 & $-5,2188$ \\
\hline 19 & 5,4146 & 0,1933 & $-0,0322$ & 0,0612 & & 4,7617 & 0,3215 & $-0,0372$ & 0,0610 & \\
\hline $\begin{array}{l}\text { Genéricos obtidos } \\
\text { por Stepwise }\end{array}$ & bo & $b 1$ & $b 2$ & $b 3$ & $b 4$ & bo & $b 1$ & $b 2$ & b3 & b4 \\
\hline 20 & 1,7555 & 0,0609 & $-0,2723$ & $-3,0342$ & 0,0000 & & & & & \\
\hline 21 & $-2,0166$ & 0,0416 & $-0,0178$ & $-1,8582$ & 4,0613 & & & & & \\
\hline 22 & & & & & & 0,3107 & 0,1030 & 0,7610 & $-0,2051$ & $-1,5585$ \\
\hline 23 & & & & & & 7,8735 & 0,0695 & $-0,0299$ & $-5,6264$ & $-0,1349$ \\
\hline
\end{tabular}

Os níveis de precisão, tanto para as parcelas temporárias, como para combinação das temporárias com as testemunhas das permanentes, apresentaram bons resultados (tab. 10), com erro padrão da estimativa que variaram de $10,57 \%$ a $14,81 \%$ e I.A. de 0,558 a 0,828 . Os piores ajustes foram obtidos com os modelos 13 (Curtis) e 14 (Blanco-Jorge) e o melhor, escolhido na literatura, foi o modelo 15 (Scolforo) que envolve além do diâmetro $(d)$, a idade, a altura dominante $\left(h_{d o m}\right)$ e o diâmetro da área transversal média $\left(d_{g}\right)$. No entanto, os modelos obtidos por regressão passo a passo apresentaram ajustes ligeiramente superiores ao 15 . O modelo que se destacou em relação ao de melhor ajuste pré-selecionado, apresentando estimativas de ajuste muito próximas, foi o modelo 21 para as temporárias e o 22 para a combinação das temporárias com as testemunhas. A análise gráfica comprovou estas estatísticas apontando tendenciosidades para os outros modelos.

Normalmente, quanto maior o número de observações melhor a qualidade do ajuste. Isto foi constatado quando se agregou dados unindo as testemunhas das parcelas permanentes às parcelas temporárias. $\mathrm{O}$ resultado final demonstrou que o modelo $15 \mathrm{se}$ destacou em ambos os casos. No entanto, quando se lança mão do uso de regressão passo a passo, que permite avaliar a contribuição de cada variável quando incorporado ao modelo em desenvolvimento, pode-se construir um modelo matemático descritivo adequado aos propósitos de uma investigação científica, ou seja, o uso de modelos elaborados especificamente para a pesquisa que se está trabalhando. Neste sentido, se destacaram os modelos 22 e 23 obtidos pelo processo regressão passo a passo, conforme pode ser observado na tabela 10 .

$\mathrm{O}$ uso de modelos genéricos, quando se quer melhorar os parâmetros de precisão, é muito útil, porque se trabalha com variáveis independentes que especificam as características do povoamento, tais como idade, sítio e densidade. No entanto, quando não se tem disponível dados como estes, é conveniente estratificar os dados, ajustando equações hipsométricas ao nível de unidade amostral em inventários florestais ou, como no caso das parcelas permanentes, por idade dentro de cada sítio e densidade inicial. No entanto, quando se dispõe de muitos dados e variáveis do povoamento, é recomendado o uso de equações genéricas. 
Com base nos dados empregados nesta pesquisa, recomenda-se, para a bracatinga, o uso dos seguintes modelos genéricos 15, 22 e
23. Todos estes modelos englobam as variáveis diâmetro e altura dominante que absorvem as variações de idade e sítio.

Tabela 10: Estatísticas correspondentes aos modelos genéricos ajustados para as parcelas temporárias e para as parcelas temporárias em conjunto com as testemunhas das permanentes

Table 10: Statistics corresponding to the fitted generic models for the temporary plots alone and for the temporary plots together with the control permanent plots

\begin{tabular}{c|c|c|c|c}
\hline & \multicolumn{2}{|c|}{$\begin{array}{c}\text { Parcelas } \\
\text { Temporárias }\end{array}$} & \multicolumn{2}{c}{$\begin{array}{c}\text { Parcelas temporárias+ } \\
\text { testemunhas das permanentes }\end{array}$} \\
\hline \hline Modelos Genéricos & & & & $\mathrm{S}_{\mathrm{yx}} \%$ \\
\hline $\mathbf{1 3}$ & I.A. & $\mathrm{S}_{\mathrm{yx}} \%$ & I.A. & 14,378 \\
$\mathbf{1 4}$ & 0,580 & 14,444 & 0,680 & 14,511 \\
$\mathbf{1 5}$ & 0,558 & 14,817 & 0,674 & 10,573 \\
$\mathbf{1 6}$ & 0,777 & 10,532 & 0,827 & 12,202 \\
$\mathbf{1 7}$ & 0,764 & 10,823 & 0,806 & 11,800 \\
$\mathbf{1 8}$ & 0,736 & 11,468 & 0,754 & 10,960 \\
$\mathbf{1 9}$ & 0,748 & 11,191 & 0,784 & \\
\hline \hline \multirow{2}{*}{ Modelos por Stepwise } & 0,762 & 10,879 & 0,814 & - \\
\hline $\mathbf{2 0}$ & & & & - \\
$\mathbf{2 1}$ & I.A. & $\mathrm{S}_{\mathrm{yx}} \%$ & I.A. & $\mathrm{S}_{\mathrm{yx}} \%$ \\
$\mathbf{2 2}$ & 0,777 & 10,536 & - & 10,542 \\
$\mathbf{2 3}$ & 0,781 & 10,430 & - & 10,616 \\
\hline
\end{tabular}

Legenda: I.A. - índice de Ajuste de Schlaegel, $\mathrm{S}_{\mathrm{yx}} \%$ - erro padrão da estimativa em percentual

\section{CONCLUSÕES E RECOMENDAÇÕES}

Baseado nos estudos realizados, pôdese chegar às seguintes conclusões:

- Dentre os modelos tradicionais de relação hipsométrica, o modelo 10 (Curtis): foi o mais adequado para estimar alturas em povoamentos nativos de bracatinga na Região Metropolitana de Curitiba, o qual deve ser ajustado para parcelas do inventário florestal.

- Quando se dispôs de variáveis do povoamento, tais como: idade, altura dominante, densidade, diâmetro médio quadrático, os modelos hipsométricos de melhor performance foram: o modelo 15 de (Scolforo) e os modelos de número 22 e 23 obtidos por regressão passo a passo, os quais podem ser usados como modelos genéricos que abrangem tanto as parcelas permanentes como as temporárias.

Como recomendação, sugere-se uma intensificação de pesquisas voltadas à evolução de conhecimentos e informações disponíveis sobre o manejo da bracatinga, de forma que possibilitem tomadas de decisão corretas e econômicas; e o contínuo inventário desta espécie, para que se tenham dados em maior quantidade e seja possível uma avaliação cada vez mais dinâmica do comportamento da mesma.

\section{REFERÊNCIAS}

AZEVEDO, C.P.; MUROYA, K.; GARCIA, L.C.; LIMA, R.M.B.; MOURA, J.B.; NEVES, E.J.M. Relação hipsométrica para quatro espécies florestais em plantio homogêneo e em diferentes idades na Amazônia ocidental. Boletim de Pesquisa Florestal, Colombo, n. 39, p. 5-29, 1999.

BAGGIO, A.J.; CARPANEZZI, A.A.; GRAÇA, L.R. \& CECCON, E. Sistema agroflorestal tradicional da bracatinga com culturas agrícolas anuais. Boletim de Pesquisa Florestal, Colombo, n. 12, p. 73-82, jun. 1986.

BAGGIO, A.J. Estudio sobre el sistema agroforestal tradicional de la bracatinga (Mimosa scabrella Benth.) en Brasil: productividad, manejo de residuos $y$ elaboración de compost. Madrid, 1994. 242 p. Tese (Doutorado em Ingenieria de Montes). Departamento de Silvopascilcultura, Escuela Técnica Superior de Ingenieros de Montes. 
BARTOSZECK, A.C.P.S. Evolução da distribuição diamétrica e da relação hipsométrica em função dos fatores idade, sítio e densidade inicial em bracatingais da região metropolitana de Curitiba. Curitiba, 2000. 214 p. Dissertação (Mestrado em Ciências Florestais). Curso de Pós-Graduação em Engenharia Florestal, Setor de Ciências Agrárias, Universidade Federal do Paraná.

BLANCO-JORGE, L. A. Equação de relação hipsométrica para povoamentos de Pinus elliottii Elgelm na Floresta Nacional de Três Barras, SC. Brasil Florestal, Brasília, DF, n. 56, p. 41-47, 1984.

CURTIS, R. O. Height diameter and height diameter age equations for second growth Douglas-fir. Forest Science, Washington, v. 13, n. 4, p. 365-375, 1967.

EMBRAPA. Centro Nacional de Pesquisa de Florestas (Curitiba, PR). Manual técnico da bracatinga (Mimosa scabrella Benth). Curitiba: EMBRAPA-CNPF, 1988. 70 p. (Série Documentos, n. 20).

HOEHNE, J.C. A bracatinga ou Abracaatinga. São Paulo: Secretaria da Agricultura, Indústria e Comércio do Estado de São Paulo, 1930a. 47 p.

IAPAR. Cartas climáticas do Estado do Paraná: 1994. Londrina: IAPAR, 1994.

KLEIN, R.M. O aspecto dinâmico do pinheiro do Paraná. Sellowia, Itajaí, v. 12, n. 12, p. 17-44, 1960.

MAACK, R. Geografia física do Estado do Paraná. 2 ed. Rio de Janeiro: J. Olympio; Curitiba: Secretaria de Cultura e do Esporte do Governo do Estado do Paraná, 1981. 450 p.

MACHADO, S.A., BASSO, S.F., BEVILACQUA JR, V.G. Teste de modelos matemáticos para o ajuste da relação hipsométrica em diferentes sítios e idades para plantações de Pinus elliottii no Estado do Paraná. In: $1^{\circ}$ CONGRESSO FLORESTAL PANAMERICANO, $\quad 7^{\circ}$ CONGRESSO FLORESTAL BRASILEIRO, Curitiba. Anais... São Paulo: Sociedade Brasileira de Silvicultura, v 2, p. 553-556, 1993.

MACHADO, S.A., BAYLEY, R.L.; BASSO, S.F., BEVILACQUA JR, V.G. Análise do comportamento da relação hipsométrica com respeito à idade para plantações de Pinus elliotti no Estado do Paraná. Cerne, Lavras, v.1, n. 1, p. 5-12, 1994.

MACHADO, S.A.; OLIVEIRA, E.B. de; CARPANEZZI, A.A.; BARTOSZECK, A.C.P.S. Classificação de sítio para bracatingais na região metropolitana de Curitiba. Boletim de Pesquisa Florestal, Colombo, n. 35, p. 21-37. 1997.

MARTINS, R. Livro das árvores do Paraná. Curitiba: Diretoria Regional de Geografia do Estado do Paraná, 1944. 247 p.

MAZUCHOWSKI, J.Z. Organização da reposição florestal. Curitiba: Projeto FAO/GCP/BRA/025/FRA, 1990. 126 p. (Série Subsídios Florestais n. 2).

PIZATTO, W. Avaliação biométrica da estrutura e da dinâmica de uma Floresta Ombrófila Mista, em São João do Triunfo PR. Curitiba, 1999. 172p. Dissertação (Mestrado em Ciências Florestais). Curso de Pós-Graduação em Engenharia Florestal, Setor de Ciências Agrárias, Universidade Federal do Paraná.

PRODAN, M. HOLZMESSLEHRE. J.D. Sauerländers Verlag, Frankfurt Am. Main. 1965. $644 \mathrm{p}$

SCOLFORO, J.R. Mensuração Florestal 3: Relações quantitativas: em volume, peso e a relação hipsométrica. Lavras: UFLA/ FAEPE, 1993. $292 \mathrm{p}$.

TONON, A.E.N. Efeitos da densidade inicial e do sítio sobre o crescimento e a produção de bracatingais da Região Metropolitana de Curitiba. Curitiba, 1998. 209 p. Dissertação (Mestrado em Ciências Florestais). Curso de Pós-Graduação em Engenharia Florestal, Setor de Ciências Agrárias, Universidade Federal do Paraná. 